\title{
Impacto da morte do filho sobre a conjugalidade dos pais
}

\author{
The impact of a child's death \\ on the marital relationship of the parents
}

Ana Bárbara Morelli ${ }^{1}$

Fabio Scorsolini-Comin ${ }^{1}$

Manoel Antônio dos Santos ${ }^{2}$

${ }^{1}$ Departamento de Psicologia, Universidade Federal do Triângulo Mineiro. Av. Getúlio Guaritá $159 / 3^{\circ}$, Abadia. 38.025-440 Uberaba MG. scorsolini_usp@yahoo.com.br ${ }^{2}$ Departamento de Psicologia, Faculdade de Filosofia Ciências e Letras de Ribeirão Preto,

Universidade de São Paulo.
Abstract The scope of this qualitative study was to understand the experience of the couple who lost a child stricken by cancer,focusing on the impact of death on the marital relationship. The methodological strategy used in this paper was the case study, seeking to describe the process of elaboration of mourning and the impact of the son's death on the parents' marital relationship. The couple who participated in the study had been together for 39 years and had lost their youngest son three years earlier. The spouses were interviewed individually and then together. Semi-structured interview scripts were used for this purpose. It was established that the religious community to which the couple belongs has been the main source of support in dealing with the mourning process, although its precepts may prevent the free expression of their suffering, particularly in the wife's case. Although the couple has remained together, the marital relationship was shaken after their son's death. The couple had difficulty in talking about their marriage, though the wife pointed to the absence of their son as one of the reasons for the change in their marital relationship. The marital relationship and religiosity/spirituality emerged as important dimensions to be addressed by health staff in attending bereaved families.

Key words Death, Marital relationship, Mourning, Cancer
Resumo O objetivo deste estudo qualitativo foi compreender a experiência do casal que perdeu um filho acometido por câncer, focalizando o impacto da morte sobre a relação conjugal. A estratégia metodológica utilizada foi o estudo de caso, buscando descrever o processo de elaboração do luto e a repercussão da morte do filho sobre a conjugalidade dos pais. Participou do estudo um casal unido havia 39 anos, que três anos antes perdera o filho mais novo. Os cônjuges foram entrevistados individualmente e, em um segundo momento, conjuntamente. Foram utilizados roteiros de entrevista semiestruturada. Observouse que a comunidade religiosa da qual o casal faz parte tem sido a principal fonte de apoio na elaboração do luto, embora seus preceitos possam, no caso da esposa, impedir a livre expressão de seu sofrimento. Ainda que o casal tenha permanecido unido, a conjugalidade ficou abalada após a morte do filho. Os cônjuges mostraram dificuldade em discorrer sobre o casamento, sendo que a esposa apontou a ausência do filho como um dos motivos para a mudança ocorrida no relacionamento conjugal. A conjugalidade e a religiosidadelespiritualidade despontaram como dimensões importantes a serem abordadas pelas equipes de saúde no atendimento aos familiares enlutados.

Palavras-chave Morte, Conjugalidade, Luto, Câncer 


\section{Introdução}

A morte é um tema que desperta temor e fascínio no ser humano, sendo parte inevitável do desenvolvimento vital. O medo da morte faz-se necessário para proteger a vida. Essa consciência da finitude é incitada quando morre alguém próximo, ativando diversos outros temores, como os derivados do abandono, perda de partes do selfe angústia frente ao desconhecido ${ }^{1,2}$.

Quando têm um filho, via de regra, os pais projetam um futuro promissor, que consideram adequado para ele. Os pais se preparam para a chegada do filho, criam expectativas acerca da criança e atribuem significados à experiência da parentalidade $^{3}$. Na perspectiva psicanalítica, por meio dos filhos é que os genitores revivem o narcisismo perdido após a passagem da etapa infantil e reivindicam tudo o que a vida adulta, de algum modo, lhes negou, além de burlarem a inexorável consciência da finitude ${ }^{4}$. Quando a vida apresenta obstáculos que comprometem o plano que delinearam para o filho, como uma doença potencialmente fatal, esse acontecimento resulta em uma ferida narcísica nos genitores. Portanto, qualquer desvio no projeto de vida traçado pelo casal destinado ao filho pode desestruturá-los ${ }^{4}$. A morte de um filho, na maioria dos casos, é inesperada, de modo que, segundo a ordem natural e cronológica, os mais velhos deveriam morrer primeiro, o que nem sempre ocorre $\mathrm{e}^{1,5-7}$.

O luto é um processo que vem responder naturalmente ao rompimento do vínculo afetivo com o outro, à perda do objeto amado, que mobiliza sentimentos dolorosos, sofrimento, tristeza, desinteresse por atividades até então consideradas prazerosas, entre outros sentimentos e comportamentos de consternação que caracterizam as reações de pesar ${ }^{8}$. A maneira como a pessoa lida com a perda e elabora o luto dependerá de uma soma de fatores, como a relação estabelecida com a pessoa que veio a óbito, a idade e o sexo do enlutado, como ocorreu a perda, as circunstâncias sociais, a estrutura psicológica do enlutado, sua capacidade de resiliência, entre outros?.

Uma morte brusca exige dos enlutados um rompimento repentino, de modo que não houve uma preparação prévia, o que é comum nos casos de acidentes. Em doenças que exigem tratamento por longo tempo, normalmente se desenvolve um processo de luto antecipatório ${ }^{10}$. No caso de doenças graves como o câncer, esse processo se inicia desde a comunicação do diagnóstico e abrange não só o paciente, como os familiares ${ }^{5}$.

Nesse contexto, a elaboração do luto antecipatório dependerá também do acolhimento ofe- recido ao enlutado, se recebeu ajuda profissional e apoio dos membros familiares, e como se estabeleceu a dinâmica conjugal. Desse modo, a conjugalidade emerge como um aspecto importante de ser investigado no contexto do luto pela perda de um filho. A conjugalidade compreende a interação do casal, envolvendo os aspectos trazidos por cada cônjuge de suas famílias de origem, bem como o modo como esses elementos se articulam no cotidiano conjugal e criam um modo particular do casal, sua identidade ${ }^{11,12}$.

Poucos estudos focalizam a experiência dos pais enlutados e, especialmente, os efeitos da experiência da perda sobre o relacionamento conjugal dos mesmos. Considerando essa lacuna do conhecimento, o presente estudo foi delineado a partir da hipótese de que a morte de um dos filhos do casal poderia repercutir também na conjugalidade dos pais. Também se considerou a premissa de que a parentalidade impacta a conjugalidade, despertando sentimentos que podem promover maior aproximação ou distanciamento do casal $^{13}$. Nessa direção, o objetivo deste estudo foi compreender a experiência do casal que perdeu um filho acometido por câncer, focalizando o impacto da perda sobre a relação conjugal e seus reflexos no processo de elaboração do luto.

\section{Método}

Trata-se de um estudo de corte transversal, fundamentado na abordagem qualitativa ${ }^{14}$. Para alcançar o objetivo proposto, adotou-se como estratégia metodológica o estudo de caso, no qual se buscou apresentar um recorte da repercussão da morte de um filho, devido ao câncer, na união de um casal. Esse delineamento metodológico mostrou-se apropriado por permitir uma análise aprofundada de um caso. Existe, por um lado, uma limitação na extensão da casuística investigada, mas, por outro, essa estratégia favorece uma abordagem em profundidade do fenômeno focalizado, com ênfase na constituição da subjetividade humana ${ }^{15}$. O estudo de caso permite lançar um olhar diferenciado acerca de como a morte pode impactar a conjugalidade dos pais. Foram respeitados os preceitos éticos da pesquisa envolvendo seres humanos. O estudo foi aprovado pelo Comitê de Ética em Pesquisa.

Participou deste estudo um casal heterossexual composto por um homem de 63 anos e uma mulher de 57 anos, que estavam casados havia 39 anos. Os critérios de inclusão foram: estar casado ou em união estável; ter perdido um filho por câncer há no mínimo dois anos e no máxi- 
mo cinco anos; ter capacidade cognitiva e de comunicação preservadas para participar da entrevista.

Os participantes, identificados como Bento e Margarida (nomes fictícios), residem em uma cidade do interior do Estado de São Paulo. O casal declarou ser praticante da doutrina espírita. Tiveram dois filhos: o filho primogênito é casado, pai de duas crianças; o filho caçula, Willian (nome fictício), descobriu que estava com câncer nos testículos aos 23 anos e faleceu aos 27. Bento acompanhou todo o processo de tratamento do filho, que ocorreu em um hospital de uma cidade de médio porte do interior do Estado de São Paulo.

Margarida é dona de casa e estudou até o quinto ano do ensino fundamental. Foi educada em uma família de tradição católica e, por isso, afirma que ainda se considera católica, embora frequente o centro espírita kardecista, que conheceu por meio da prima. Bento completou o ensino fundamental e trabalhava como mecânico. Os cônjuges são oriundos de um contexto sociofamiliar de nível socioeconômico baixo. Bento trabalha desde os 11 anos de idade. Eles se casaram na cidade de São Paulo e, após três anos de união, voltaram a morar no interior, na cidade de origem de ambos.

O contato com o casal ocorreu por telefone, no qual foi exposto pela pesquisadora a temática e o objetivo do estudo. Os cônjuges foram convidados a participar de forma voluntária e, uma vez obtida sua concordância, agendou-se a primeira entrevista. Após assinatura do Termo de Consentimento Livre e Esclarecido, iniciou-se o processo de coleta de dados.

A coleta foi realizada a partir de um roteiro de entrevista semiestruturada, que continha perguntas que investigavam a experiência de cada cônjuge e do casal acerca da doença e morte do filho. $\mathrm{O}$ foco da entrevista foi dirigido ao enfrentamento da situação adversa, atentando-se para as possíveis repercussões da perda do filho no cotidiano conjugal.

As entrevistas ocorreram em situação face a face na residência do casal. Nesse momento, estavam presentes na casa somente os cônjuges. A coleta de dados foi dividida em dois momentos. Primeiramente, os cônjuges eram entrevistados separadamente, visando a entender como cada um enfrentou a morte do filho e percebeu seu impacto no enlace conjugal, seguindo-se o roteiro de entrevista semiestruturado. Em seguida, ocorreu a entrevista com o casal, também a partir de um roteiro semiestruturado específico, a fim de compreender como o casal percebeu o próprio casamento após a perda do filho. Desse modo, foram realizadas três entrevistas em um único dia: com o esposo, com a esposa e com o casal.

As entrevistas foram audiogravadas e, posteriormente, transcritas na íntegra e literalmente, e submetidas à análise de conteúdo temática, na qual se buscou evidenciar conteúdos expressos nos relatos que permitissem elucidar o fenômeno investigado. Foram realizadas análises verticais (de cada entrevista, separadamente) e horizontais (do conjunto constituído por todas as entrevistas), de modo a destacar as semelhanças e diferenças nas experiências relatadas. A análise de conteúdo na modalidade temática foi implementada em três etapas: pré-análise do material, exploração do material e tratamento dos dados obtidos, e interpretação com base no referencial teórico adotado ${ }^{16}$. Os resultados foram subdivididos em categorias temáticas, de acordo com os conteúdos expressos nas falas dos entrevistados.

\section{Resultados e Discussão}

Da análise do corpus emergiram as seguintes categorias de análise: (a) A experiência dos genitores diante da morte do filho; (b) Os efeitos da morte do filho na dinâmica conjugal; (c) Percepção acerca do filho falecido de acordo com o momento experienciado pelos enlutados; (d) As consequências da morte de um membro do grupo na organização familiar; e (e) Religião: ferramenta encontrada para manejar o processo de luto.

\section{A experiência dos genitores diante da morte do filho}

Willian foi diagnosticado com câncer nos testículos quando tinha 23 anos. Estava noivo na época. Segundo os pais, o filho sempre teve uma saúde frágil, sendo que seu primeiro adoecimento ocorreu logo após a festa de seu primeiro ano de vida. A partir de então, o pai destaca vários eventos relacionados a adoecimentos enfrentados pelo filho caçula, situações encaradas como aparentemente simples (como lesões ao jogar futebol ou pequenos ferimentos em brincadeira com os amigos), mas que acabavam se agravando. Quando receberam o diagnóstico do câncer, foi o pai seu principal cuidador e acompanhante. Tiveram de se deslocar para uma cidade próxima, em busca de melhores condições de tratamento. $\mathrm{O}$ fato de acompanhar o filho durante esse processo, que incluiu quimioterapia, pode ter contribuído para a elaboração satisfatória do luto antecipatório.

Ao ver o sofrimento e a progressiva degradação física de Willian, o pai passou a se conformar 
gradualmente com a possibilidade de morte, antes mesmo que ela se tornasse realidade, vendoa como uma alternativa ao alívio imediato do sofrimento do filho:

... eu acompanhei ele desde o começo, eu que ia para [cidade onde era realizado o tratamento] com ele todo dia fazer terapia, então eu acompanhei tudinho, tudinho, você sabe que eu cheguei até, de ver o sofrimento dele, o que ele passava, eu cheguei num ponto assim de até me conformar, me conformar um pouco, sabe? (Bento, entrevista individual).

O termo "luto antecipatório" foi inicialmente utilizado por Lindermann ${ }^{17}$ ao perceber que mulheres experienciavam sintomas e comportamentos inerentes a pessoas enlutadas antes mesmo da despedida dos maridos que iriam para a guerra. Posteriormente, o conceito foi usado para descrever o luto específico que ocorre com cuidadores/acompanhantes de pacientes com doenças graves e prolongadas. Nesses casos, frente a eventos extremamente estressantes e desgastantes, exige-se da família paciência e uma elaboração da perda do ente ainda em vida. Ao conviver com a debilidade progressiva, o sofrimento e a degradação do corpo, o cuidador acaba interpretando a morte como um alívio para o sofrimento do ente querido. No entanto, quando esta é consumada, pode despertar nos enlutados um sentimento de culpa.

Nos relatos de Margarida percebe-se que ela apresenta grande dificuldade de aceitação da perda do filho. Consequentemente, a elaboração do luto não se processou de modo saudável. A mãe vivencia conflitos que envolvem ambivalência emocional e sentimento de culpa, o que prejudica o desenvolvimento de seu luto de forma satisfatória. Margarida recorre à doutrina espírita para auxiliá-la nesse processo. Segundo ela, a doutrina prega que ela deve se adaptar à mudança, evitando a tristeza. Quando se percebe expressando tristeza frente à dolorosa perda, sente que pode estar traindo os fundamentos de sua doutrina:

... a gente tenta trazer na fisionomia da gente alegria, mas o coração continua assim. Só que também eu não posso, eu ouvi a doutrina, então por que eu vou lá ouvir a doutrina se eu não cumpri certinho como eles falam lá pra gente que a gente tem que fazer? Então, filha, não fica bem, então a gente tem que tá alegre aqui pra ele, tá alegre lá comigo também de ver, porque ele não vai querer que eu fico aqui triste, né?, então a gente tem que esforçar, né?, pra gente ser... (Margarida, entrevista individual).
Pelos relatos paternos, observa-se uma expressão de maior aceitação pela morte do filho. A mãe faz o contraponto, parecendo ainda viver de modo visceral a experiência do luto, destacando a presença do filho perdido inclusive quando comenta sobre a sua história de vida individual. Conta que "tem" dois filhos e já apresenta a condição do mais novo, decorrendo disso uma fala que recupera, a todo momento, a memória de Willian. A religião espírita é trazida nesses momentos como uma fonte de conforto, como um modo de refrear sua dor incontornável, solicitando dela um novo posicionamento diante da vida e de seu sofrimento. Margarida não se sente em condições de realizar isso plenamente, motivo pelo qual se vê como alguém que burla os preceitos dessa religião. Há que se considerar que Margarida apresenta-se também como católica praticante, justificando que tem recorrido ao espiritismo com muita frequência depois da morte de Willian.

O processo de elaboração do luto antecipatório depende do suporte oferecido aos indivíduos enlutados. Ajuda profissional e dos membros familiares são fontes de apoio relevantes. Mas a elaboração também depende do modo como se estabeleceu a dinâmica conjugal. Se os cônjuges estiverem vivenciando reações distintas, nas quais um experimenta aceitação da morte enquanto o outro rejeita completamente essa ideia, podem surgir conflitos e discrepância entre os comportamentos e atitudes do casal ${ }^{18}$.

\section{Os efeitos da morte do filho na dinâmica conjugal}

Bento mostra dificuldades de falar sobre como ficou o casamento após a morte do filho. Relata que houve mudanças, mas que essas não abalaram o relacionamento preexistente. Verbaliza que sua esposa ainda sofre muito com a per$\mathrm{da}$, atribui essa dificuldade de elaboração ao fato de ela ser "a mãe", hipervalorizando o vínculo mãe-filho. Ao se reestruturar após a perda, Bento diz que tentou ajudar toda a sua família a enfrentar o processo:

Uma hora dessas é difícil ajudar, sabe, a gente tenta, mas fazer o quê? Uma mãe sentir assim, que sente mesmo, então a gente procura dar carinho, né?, carinho, ajudar, foi difícil [...] Agora, depois de, para você ver, vai fazer três anos, agora que ela tá mais... (Bento, entrevista individual).

Margarida expõe que seu esposo não demonstra seus sentimentos, para manter uma posição de "durão", normalmente atribuída ao 
provedor do lar. Mas não compreende que, de fato, ele viveu o luto de forma individual e diferenciada do restante da família e dela. Margarida menciona, por diversas vezes, o quanto a relação conjugal está afetada e o quanto se sente culpada por isso, visto que não se sente a mesma pessoa após a morte de Willian. Verbaliza claramente que precisa de ajuda:

Ah, casamento é igual tô te falando, é assim: ele é uma pessoa muito boa, não tenho, nossa, mas as coisas veio, eu fiquei assim depois desse acontecimento do meu filho, que, sabe, eu, ele nem merece assim [...] a gente continua a mesma coisa com carinho um com outro, mesma coisa, mas mudou, mudou porque eu [...] não tenho mais aquela coisa como eu tinha, de viver mais naquela vida mais à vontade de, mais... aí já me fechei mais... (Margarida, entrevista individual).

Margarida sente falta de maior união do casal, mas não consegue expressar com facilidade o que realmente está faltando. Em diversas ocasiões ressalta as características positivas do esposo, dizendo que ele é o homem ideal e que seu casamento foi um dos eventos mais importantes da sua vida:

A gente continua a mesma coisa, tudo que era, assim. Só que a gente se uniu mais em partes assim, acho que a gente tinha que ser mais unido, não que a gente brigue, não briga de jeito nenhum, só que, assim, a gente ficou um pouco distante, entendeu? (Margarida, entrevista individual).

Ambos concordam que o casamento não é o mesmo, mas não conseguem perceber que estão vivenciando momentos distintos do luto, o que pode contribuir para gerar o distanciamento do casal. A esposa se sente sozinha por ver que está se posicionando de forma distinta dele frente à problemática. Desse modo, ela conclui que, por não se portar como o esposo e por expressar sua dor, é responsável pelas consequências no relacionamento, cobrando de si mesma, de forma exigente e constante, uma mudança que não está conseguindo realizar sozinha. Ainda em relação às repercussões dessa experiência para a conjugalidade, pôde-se vislumbrar o padrão de interação do casal na entrevista realizada com os dois cônjuges:

Margarida: E o casamento? E o casamento? Fala pra ela do casamento depois do falecimento dele, aí é difícil, né? Aí é difícil, difícil, aí é bastante difícil, mas, né? não é fácil, difícil, depois disso daí foi.

Bento: Você perguntou se mudou alguma coisa? Margarida: $E$.

Bento: Que muda, muda. Que muda, muda um pouco.
Margarida: Porque é uma falta, né? uma falta muito grande, não tem como falar que não muda. Acho que é difícil. Se você fazer uma pesquisa com um casal, igual aconteceu com a gente, de falar que não muda, porque eu acho que vai falar que muda, acho que vai falar que muda (Margarida e Bento, entrevista com o casal).

Pode-se observar que o marido mostra-se mais reticente ao comentar sobre a repercussão da perda do filho para a dinâmica conjugal. A esposa, no entanto, não apenas destaca que houve uma mudança, como apresenta o filho mais novo como uma parte importante de sua conjugalidade, como se seu casamento também estivesse atrelado à experiência da parentalidade. Logo, se há uma lacuna aberta na parentalidade, o mesmo ocorrerá em relação ao relacionamento do casal. O enlutamento de Margarida é tão proeminente a ponto de sua dor emocional atravessar o modo como ela descreve a relação com o marido.

A morte de um filho é evento crítico e dilacerante, na medida em que rompe com a ordem natural e cronológica, subvertendo expectati$\operatorname{vas}^{1,6}$. Em relação ao casal Bento e Margarida, nota-se que, a despeito dos esforços, o marido não consegue se aproximar efetivamente da esposa, a ponto de não perceber sua vulnerabilidade, o que acirra sentimentos de isolamento e solidão no decurso do processo de enlutamento.

\section{Percepção acerca do filho falecido de acordo com o momento experienciado pelos enlutados}

Os cônjuges descrevem o filho Willian de forma distinta. Bento considera que o filho era rebelde, mas sem causar grandes problemas aos pais. Destaca que ele sempre foi um bom aluno, mas que se comportava de modo diferente em casa e com as outras pessoas.

Foi um menino, ele era um pouco rebelde, sempre foi um pouco rebelde, sabe? Mas o mais velho já é mais amoroso, entendeu? Mais assim, apegado, ele não... eu não sei porque [...] Ele era mais, não sei se amoroso, parece que ele se dava bem com as pessoas, em casa ele era sempre carrancudo, brincava com a gente normal, assim, mas não tanto. (Bento, entrevista individual).

Ao comentar sobre a condição de adoecimento do filho por câncer, o pai coloca o filho em uma posição de sensibilidade, de ter sido vulnerável e "diferente" desde a infância, como se a marca do adoecer de alguma forma já estivesse presente em sua vida desde o início. Infere-se que 
Bento pode ter construído essa definição de vulnerabilidade perene do filho a partir da sua vivência no acompanhamento quimioterápico, passando a atribuir esse significado a Willian. Para consolidar sua justificativa, associa durante a entrevista vários acontecimentos que ocorreram ao longo da vida do filho que, para Bento, o caracterizam como vulnerável.

Ao contrário de Bento, que define o filho como revoltado e vulnerável, a mãe o delineia como amoroso, carinhoso e "maravilhoso". Destaca que as únicas situações de aborrecimento que ele trouxe foram por conta das namoradas que teve. Segundo a mãe, ele era muito namorador e desejado por muitas mulheres, o que é significado por Margarida como uma característica positiva. Compreende-se que a mãe apresenta uma idealização acerca da beleza e do poder de sedução do filho, o que é comum em quem está iniciando o processo de luto:

Eu falar, nem tem, não sei citar um defeito nele, não porque, né?: 'ah, é mãe, é lógico, mãe não acha', não, não é, porque se tivesse alguma coisa a gente tem que falar, né? Mas eu não tenho o que falar nada não, de jeito nenhum. Nunca me deu trabalho em nada, nada, o trabalho que ele me deu eram as namoradas... (Margarida, entrevista individual).

Pessoas que se encontram no início do processo de luto apresentam uma tendência de destacar somente os aspectos positivos do ente falecido ao descreverem suas lembranças ${ }^{19}$. Portanto, a "idealização" é um mecanismo de defesa do familiar que se encontra em luto, que ignora os aspectos negativos e superestima os positivos do falecido. Isso deve ser levado em conta ao se analisar os depoimentos dos enlutados, mas também se faz necessário pensar na hipótese de que o ente falecido possa realmente ter tido tais atributos. Outra explicação alternativa é que tal visão tenha sido gerada a partir de uma redefinição da relação ou do ritual de despedida, na qual passam a recordá-lo com caráter genuíno, puro e com carinho. Recordar é uma necessidade do enlutado. A recordação tem a função de manter preservada a relação com o falecido ${ }^{20}$.

Portanto, a fase na qual os enlutados se encontram e a relação que estabeleceram com o filho são fatores que podem interferir na maneira como percebem o filho e recordam suas experiências com o membro falecido. Não se trata de comparar as percepções do pai e da mãe, mas de assinalar que tais falas podem ser indicativas do modo singular como o luto tem se processado por cada cônjuge.

\section{As consequências da morte de um membro do grupo na organização familiar}

Margarida descreveu como os demais membros da família reagiram à morte de Willian:

Nossa, abalou, a família também. Não posso falar que teve o mesmo sentimento que o meu porque eu sou mãe, é diferente, mas quase igualou, porque ele era muito querido pela família, principalmente pelas minhas irmãs, minhas irmãs, minha cunhada e... Nossa, eles sentiram. Tem uma sobrinha minha que é casada e até hoje, ela era muito apegada nele, nossa, então ela sentiu demais (Margarida, entrevista individual).

De acordo com o depoimento de Margarida, a família era mais unida quando Willian estava vivo. Refere que vários parentes eram mais presentes em sua casa antes da morte do filho. Ao mesmo tempo, ela julga que os parentes iam até a sua casa por causa de Willian, que era muito querido. Bento relata de modo similar a repercussão da morte no grupo familiar, destacando que houve certo afastamento de alguns familiares após o ocorrido.

Diante da perda de um membro familiar, impõe-se o exercício tanto de um luto individual quanto grupal, visto que haverá uma necessidade de reestruturação e construção de uma nova identidade familiar, na qual os papéis devem ser redistribuídos para que não haja sobrecarga em um dos membros. A reorganização e a livre expressão dos sentimentos são indispensáveis à família enlutada, visando a evitar uma crise no seio familiar, pois a família tende a se fechar para o meio externo diante da perda. Nesse contexto, o auxílio profissional pode facilitar a comunicação entre os familiares, promovendo a abertura de canais por onde podem ecoar as lembranças e os sentimentos intoleráveis ${ }^{5,21}$.

O casal não conversa sobre morte no meio familiar. A morte é um tema silenciado, só referido esporadicamente, quando alguém próximo morre. Margarida declara que não gosta de falar sobre o tema. Na era contemporânea, a morte ainda é um tabu difícil de ser dissolvido. Mesmo diante de toda evolução tecnológica, falar de morte com naturalidade tornou-se raridade. $\mathrm{O}$ ser humano evita falar de um processo inevitável e que diz respeito a todas as pessoas, já que a morte é parte do ciclo vital. Quando o tema é debatido, normalmente as pessoas tendem a discuti-lo na posição de meros espectadores. A temática velada só tem sido discutida em espaços reservados, que a sociedade determinou como 
adequados e específicos, como velórios e hospitais $^{22}$. Ao mesmo tempo, está em marcha um processo de banalização da morte. Cada vez mais a morte permeia os meios de comunicação de massa e o arsenal bélico atual contém armas de destruição em massa que são capazes de dizimar milhares de pessoas em frações de segundo, com notável "precisão cirúrgica".

Um debate amplo e sem preconceitos deveria envolver toda a sociedade, abrangendo como a morte está sendo enfrentada e que repercussões ela tem no cotidiano das pessoas; quais são as crenças acerca da morte que sustentam nossas atitudes frente a ela; quais os valores vigentes que são transmitidos para as crianças e adolescentes quando o tema é exposto. Quanto mais esse assunto puder ser esclarecido e tratado com naturalidade, mais saudáveis serão as formas encontradas pelas pessoas para lidarem com o processo de morte e do morrer ${ }^{23,24}$. Isso permitiria que os pais que perderam seus filhos para o câncer pudessem estabelecer uma rede de apoio social confiável e abrangente, de modo a poderem atravessar a transição psicossocial inerente ao processo de luto.

\section{Religião: ferramenta encontrada para manejar o processo de luto}

$\mathrm{O}$ apego à religião e/ou espiritualidade emergiu como uma das ferramentas que têm sido utilizadas pelos pais enlutados, o que corrobora achados da literatura ${ }^{25-28}$. Segundo Bento, a doutrina espírita dissemina a solidariedade, uma característica destacada por ele como marcante de seu filho falecido e do seu maior exemplo de vida, "um senhor" espírita com o qual conviveu em São Paulo e que exerceu sobre ele o papel paterno. Bento também considera a doutrina espírita como a que oferece a explicação mais satisfatória sobre o pós-morte:

A pessoa morre e volta pra aprender o que ela fez de mal, então ela vai ver, é, ela vai passar por aquilo, né? Ver o erro, compensar o erro que ela fez na outra vida. Então ela vai, por isso ela sofre, porque, não que ela sofre também, porque eles explicam o seguinte, quando vem encarnar na pessoa, a pessoa escolhe a própria pessoa, então eu vou passar por isso, vou em tal família, nascer naquela família para ver, para mim aprender (Bento, entrevista individual).

Bento já frequentava centros espíritas desde a adolescência, na cidade de São Paulo. Referiu que Willian também praticava o espiritismo antes de receber o diagnóstico de câncer. Assim, a religião já fazia parte de suas experiências vitais e não foi selecionada a partir da experiência de sofrimento com o filho acometido pelo câncer. $\mathrm{O}$ participante destaca que as pessoas praticantes da doutrina espírita o ajudaram muito na travessia do tratamento e que encontrou nelas compreensão e apoio:

As pessoas também ajudam muito, igual lá no centro espírita que a gente vai lá, nossa, no começo todo mundo vinha conversar, conversava, consolava a gente, pessoas muito, que ajudou muito, as pessoas ajudou muito sim (Bento, entrevista individual).

Margarida também apresenta argumentos acerca de como recorreu à espiritualidade na busca por haurir forças para a superação. Ao longo de seu depoimento houve menção frequente a Deus e ao modo como os caminhos de cada um já estão planejados e predestinados antes mesmo de nascer. O participante não deixou transparecer qualquer postura de raiva, embora julgue difícil seguir todos os preceitos da religião, ainda mais quando se trata da aceitação da morte de um filho:

Precisa de muita oração! Precisa apegar muito em Deus e pedir muita força pra Ele. Ele que dá forças pra gente prosseguir o dia a dia da gente, porque o dia a dia é muito difícil. [...] Nossa, é muito difícil. Se for uma pessoa que não pega na mão de Deus, não segue uma doutrina, seja essa qual for... porque Deus é um só, só que cada um escolhe qual que quer fazer, não é fácil não, viu, entra em depressão, faz até coisa pior. Então que é fácil não é não, é muito difícil. Você perde a razão de viver, perde a razão de viver porque é difícil, muito difícil, nossa, mãe de Deus! (Margarida, entrevista individual).

Margarida também ressalta que, no centro espírita que passou a frequentar após a perda do filho por influência de uma prima, encontrou pessoas sensíveis que a acolheram. Sentir-se membro do grupo é algo que lhe dá forças. Assim como o esposo, Margarida destaca o valor da solidariedade e da humildade que a religião difunde, e que são expressas nos comportamentos das pessoas que dela participam. Margarida crê que o filho pertence a Deus e usa do preceito religioso de que é Deus quem define o último dia de cada indivíduo para trabalhar seu luto. Mostra-se resignada ao afirmar que foi feita a vontade de Deus: mas é tudo da vontade de Deus; Deus, ele dá e tira a hora que ele quiser. Desse modo, manifesta uma postura resignada diante do que houve com o filho, atribuindo a Deus a responsabilidade pelo ocorrido. Margarida afirma que 
reza muito e várias vezes ao dia para ter forças para suportar sua dor.

A literatura aponta que, nesse contexto delicado, a espiritualidade e a religiosidade são percebidas como modos de enfrentamento, aos quais os enlutados recorrem para obterem conforto, alívio para o sofrimento e busca de aceitação da perda. Isso geralmente ocorre sob a influência de premissas compartilhadas pelo grupo religioso, que apontam o modo como a morte deve ser vista e encarada, funcionando como uma espécie de guia que ordena e dá sentido para a experiência brutal da perda.

Estudos recentes têm apontado a importância da fé ou de experiências relacionadas à espiritualidade e religiosidade no percurso de tratamento de pacientes com diferentes doenças, entre elas o câncer ${ }^{25-28}$. Isso é igualmente válido para os cuidadores. A religiosidade/espiritualidade pode ser considerada uma forma de enfrentamento positivo. Envolve estratégias de enfrentamento ativo, como planejamento, reinterpretação positiva e busca de apoio social instrumental e emocional ${ }^{27,29}$. Assim, a relação com o sagrado pode ser uma estratégia de enfrentamento eficaz diante de situações consideradas difíceis, como é o caso do diagnóstico do câncer e da morte de um ente próximo em decorrência da doença.

Nesses casos, a sobrecarga física e psicológica que recai sobre os familiares deve ser acompanhada pela equipe de saúde, a fim de que o luto possa ser elaborado de modo saudável ${ }^{30,31}$. O acompanhamento deve ser oferecido, notadamente, pelas equipes que atuam nos cuidados paliativos $^{32}$. Por outro lado, a ausência de crença religiosa ou de alguma concepção acerca da mortalidade pode ser um complicador do processo de luto ${ }^{33}$. Algumas religiões disseminam a crença na existência de uma alma posteriormente ao óbito, ou seja, de uma continuidade pós-morte. Elas diferenciam-se entre si em relação aos destinos atribuídos à alma. As diferenças acontecem porque os grupos religiosos possuem uma identidade própria e fundamentos específicos de cada grupo, assim como rituais sustentados nos preceitos de cada doutrina ${ }^{6}$. Porém, todas as doutrinas convergem no que diz respeito à apresentação de uma proposta de continuidade de uma existência além da que todos conhecemos.

\section{Considerações Finais}

Os resultados obtidos neste estudo evidenciam que é notória a mudança ocorrida no enlace conjugal dos genitores após a morte do filho. Ambos expressaram com nitidez que, depois da perda, o casamento já não era o mesmo. O esposo nota a tristeza recorrente de Margarida e tenta ajudá-la, mas não sabe exatamente qual a melhor forma. A esposa se considera culpada pela mudança ocorrida na relação conjugal e destaca por diversas vezes que suas necessidades emocionais permanecem insatisfeitas. Ela não conta com um espaço seguro e permissivo no qual possa expressar sua tristeza sem sentir-se culpada, embora encontre conforto nos colegas praticantes do espiritismo. Entretanto, ao sentir-se triste, considera que está indo contra os preceitos religiosos que professa, como se a sua religiosidade/ espiritualidade devesse ser marcada necessariamente pela superação do trauma e por uma experiência amadurecida acerca da perda do filho.

Desse modo, pode-se postular que a experiência religiosa cumpriria um duplo papel na história de Margarida: (1) de um lado, prover suporte e alívio ao sofrimento insuportável, oferecendo uma explicação reconfortante acerca da morte inaceitável do filho; e (2) de outro lado, inibir e cercear a livre expressão da dor e do sofrimento, que podem ocorrer até mesmo muito tempo após a perda. Na concepção compartilhada por Margarida com os adeptos da religião, ao considerar a situação da morte do filho, ela acredita conscientemente que deve superar plenamente seu pesar. Esse processo dar-se-ia de forma linear e não comportaria avanços e retrocessos, como de fato ocorre, oscilando entre momentos de maior integração e resignação com momentos de maior fragmentação e dilaceramento emocional. No caso de Bento, essa compreensão parece mais natural e amadurecida, tanto em função de sua crença não ter sido construída em função do falecimento do filho, quanto do fato de seu processo de luto ter se dado de modo não complicado.

Os cônjuges consideram que o distanciamento emocional entre eles ocorreu porque não vivenciaram o luto de forma conjunta, mas individualmente. Bento parece esperar que Margarida se aproxime e participe de seu processo de enlu- 
tamento. Ao vislumbrar esse convite, a esposa sente-se inadequada, como se não tivesse condições de olhar para o marido sem se lembrar do filho que morreu. Assim, se por um lado a conjugalidade diante do luto é construída como um espaço de apoio mútuo, a perda também se afigura como algo que pode alimentar o distanciamento dos cônjuges. No relacionamento do casal parece predominar a primeira acepção, sendo o casamento uma instituição de acolhimento que permite o acompanhamento da experiência dolorosa. No entanto, o aspecto potente e vital da conjugalidade, ligado ao processo de construção de vínculos entre os parceiros e que demanda envolvimento, atenção e dedicação ao outro parece ter sido esvaziado após a morte do filho, o que deve ser considerado pelo casal.

Os achados deste estudo devem ser recebidos com parcimônia pela comunidade acadêmica, uma vez que o estudo de caso não permite gene- ralizações. Novos estudos são necessários para reunir as experiências de diferentes casais que perderam seus filhos, que professam diferentes crenças religiosas ou que se autodeclarem sem religião. Por outro lado, o enfoque qualitativo permitiu a exploração a fundo do caso, a partir de entrevistas em profundidade, embora o "caso" deva ser sempre compreendido em sua especificidade. As repercussões da morte do filho para a conjugalidade dos pais, bem como o enfrentamento religioso propiciado pela imersão do casal em uma prática espiritual, podem e devem ser considerados pelas equipes de saúde, notadamente aquelas envolvidas com o cenário dos cuidados paliativos. É preciso alertar os profissionais de saúde para a necessidade de fundamentarem suas intervenções não apenas em estratégias de enfrentamento positivo, como também de lançar um olhar diferenciado para o sofrimento que acomete os familiares cuidadores.

\section{Colaboradores}

F Scorsolini-Comin, AB Morelli e MA Santos participaram igualmente de todas as etapas de elaboração do artigo. 


\section{Referências}

1. Kovács MJ. Morte e desenvolvimento humano. São Paulo: Casa do Psicólogo; 1992.

2. Ambrósio DCM, Santos MA. Vivências de familiares de mulheres com câncer de mama: uma compreensão fenomenológica. Psic: Teo Pesq 2011; 27(4): 475-584.

3. Carlesso DRD. Desamparo diante da perda do filho. Rev SBPH 2008; 11(1):131-141.

4. Monti MR. Contrato narcisista e clínica do vazio. Rev Latino-Am Psicopat Fund 2008; 11(2):239-253.

5. Menezes CNB, Passareli PM, Drude FS, Santos MA, Valle ERM. Câncer infantil: organização familiar e doença. Rev. Mal-estar Subj 2007; 7(1):191-210.

6. Alarcão ACJ, Carvalho MDB, Pelloso FM. A morte de um filho jovem em circunstância violenta: compreendendo a vivência da mãe. Rev. Lat Am Enfermagem 2008; 16(3):341-347.

7. Oliveira EA, Santos MA, Mastropietro AP. Apoio psicológico na terminalidade: ensinamentos para a vida. Psic em Est 2010; 15(2):235-244.

8. Freud S. Luto e melancolia. In: Freud S. Obras Psicológicas Completas de Sigmund Freud: Volume XIV. Rio de Janeiro: Imago; 1990. p. 245-265. Original publicado em 1917.

9. Bowlby J. Perda: tristeza e depressão. São Paulo: Martins Fontes; 1985.

10. Bowlby J. Apego e perda: Perda - tristeza e depressão. São Paulo: Martins Fontes; 1998.

11. Scorsolini-Comin F, Santos MA. Correlations between subjective well-being, dyadic adjustment and marital satisfaction in Brazilian married people. Spanish J Psycho 2012; 15(1):166-176.

12. Scorsolini-Comin F, Santos MA. A medida positiva dos afetos: bem-estar subjetivo em pessoas casadas. Psic: Refl Crít 2012; 25(1):11-20.

13. Magagnin C, Kõrbes JM, Hernandez JAE, Cafruni S, Rodrigues MT, Zarpelon M. Da conjugalidade à parentalidade: Gravidez, ajustamento e satisfação conjugal. Aletheia 2003; (17/18):41-52.

14. Minayo MCS. Análise qualitativa: teoria, passos e fidedignidade. Cien Saude Colet 2012; 17(3):621-626.

15. Peres RS, Santos MA. Considerações gerais e orientações práticas acerca do emprego de estudos de caso na pesquisa científica em Psicologia. Interações 2005; 20(10):109-126.

16. Minayo MCS. O desafio do conhecimento: pesquisa qualitativa em saúde. 12a Edição. São Paulo: Hucitec; 2010.

17. Lindemann E. Symptomatology and management of acute grief. Am J Psychi 1944; 101(2):141-148.

18. Gonçalves MO. Morte e castração: um estudo psicanalítico sobre a doença terminal infantil. Psic: Ciênc Prof 2001; 21(1):30-41.

19. Bromberg MHPF. Famílias enlutadas. In: Carvalho MMMJ. Introdução à psiconcologia. Campinas: Workshopsy; 1994. p. 243-259.
20. Lisboa MC, Crepaldi MA. Ritual de despedida em familiares de pacientes com prognóstico reservado. Paidéia (Ribeirão Preto) 2003; 13(25):97-109.

21. Labate RC, Barros GC. Uma possibilidade de escuta a uma família enlutada: Ressignificando a experiência de perda. Rev SPAGESP 2006; 7(1):50-57.

22. Bendassolli PF. Percepção do corpo, medo da morte, religião e doação de órgãos. Psic: Refl Crít 2001; 14(1):225-240.

23. Borges ADVS, Silva EF, Toniollo PB, Mazer SM, Valle ERM, Santos MA. Percepção da morte pelo paciente oncológico ao longo do desenvolvimento. Psic em Est 2006; 11(2):361-369.

24. Rodriguez CF. Falando de morte na escola: o que os educadores têm a dizer? [tese]. São Paulo: Instituto de Psicologia, Universidade de São Paulo; 2010.

25. Chen YY, Koenig HG. Do people turn to religion in times of stress? An examination of change in religiousness among elderly, medically ill patients. $J$ Nerv Ment Dis 2006; 194(2):114-120.

26. Ferreira VS, Raminelli O. O olhar do paciente oncológico em relação à sua terminalidade: ponto de vista psicológico. Rev SBPH 2012; 15(1):101-113.

27. Fornazari SA, Ferreira RER. Religiosidade/espiritualidade em pacientes oncológicos: qualidade de vida e saúde. Psic: Teo Pesq 2010; 26(2):265-272.

28. Teixeira JJV, Lefèvre F. Significado da intervenção médica e da fé religiosa para o paciente idoso com câncer. Cien Saude Colet 2008; 13(4):1247-1256.

29. Alves RRN, Alves HN, Barboza RRD, Souto WMS. The influence of religiosity on health. Cien Saude Colet 2010; 15(4):2105-2011.

30. Guimarães CA, Lipp MEN. Um olhar sobre o cuidador de pacientes oncológicos recebendo cuidados paliativos. Psic: Teo Prát 2011; 13(2):50-62.

31. Melo MCB, Barros EM, Campello MCVA, Ferreira LQL, Rocha LLC, Silva CIMG, Santos NTF. O funcionamento familiar do paciente com câncer. Psic em Rev 2012; 18(1):73-89.

32. Palmeira HM, Scorsolini-Comin F, Peres RS. Cuidados paliativos no Brasil: revisão integrativa da literatura científica. Aletheia 2011; 35/36:179-189.

33. Walsh K, King M, Jones L, Tookman A, Blizard R. Spiritual beliefs may affect outcome of bereavement: prospective study. Brit Med J 2002; 324(7353): 1551-1554.

Artigo apresentado em 30/04/2013

Aprovado em 22/05/2013

Versão final apresentada em 27/05/2013 